\title{
Dynamic Change Management for Fast-tracking Construction Projects
}

\author{
by \\ Moonseo Park ${ }^{1}$
}

\begin{abstract}
Uncertainties make construction dynamic and unstable, mostly by creating non value-adding change iterations among construction processes. Particularly, when a project is fast-tracked without proper planning, those change iterations can cause the disruption of the construction process. For this reason, to effectively handle fast-tracking change iterations involved in fast-tracking need to be identified, and the dynamic behavior of construction resulting from those change iterations must be dealt with in a systematic manner. As an effort to address some of these challenging issues in fast-tracking construction, this research paper identifies different change iteration cycles involved in fast-tracking construction and observes the characteristics and behavior patterns of change. All of research findings are incorporated into a cohesive system dynamics model and the model simulation confirms that managerial decisions on change or rework should be made based on the proper assessment of their tradeoff. In addition, a case study of highway and bridge construction projects shows the potential of how fast-tracking construction can benefit from dynamic change management in real world settings.
\end{abstract}

KEYWORDS: Change, Fast-tracking, Feedback, Rework, Simulation, System Dynamics

\section{INTRODUCTION}

Shortening time-to-market has been one of the most critical factors to the success of businesses in many industries. As a result, companies have sought a method that can ensure a faster product development, most commonly focusing on product cycle time reduction through concurrent development. The construction industry is not an exception. The increasing preference of project owners and managers to fast-track construction proves the popularity of concurrent development in construction. In addition, many success stories of fast-tracking have demonstrated that the popularity of this delivery method is warranted [Huovila et al., 1994; Williams, 1995]. However, concurrent construction also has greater potential to impact the project development process than the traditional more serial method [Pena-Mora and Park, 2001].

In the literature, these potential problems are mainly attributed to the increased level of uncertainty and research efforts on fasttracking have focused on uncertainty reduction.
However, in dealing with uncertainties, most of the previous researches have not explicitly addressed how they impede construction processes, nor identified the different patterns of their impact on the project performance.

Closer observations of the design and construction process indicate that uncertainties make the construction dynamic and unstable, mostly by creating non value-adding change iterations among construction processes. Particularly, when a project is fast-tracked without proper planning, those change iterations can cause the disruption of the construction process. In addition, people's preference of change to rework can reinforce the change impact. Since construction has a physical manifestation, construction rework is normally perceived to have a bigger impact than change. As a result, construction managers tend to avoid rework on problematic tasks by changing the scope of work, in particular under time constraints. However,

\footnotetext{
${ }^{1}$ Assistant Professor, Department of Building, School of Design \& Environment, National University of Singapore, Email:bdgmp@nus.edu.sg
} 
construction sequence by triggering subsequent changes on other tasks, which often contributes to unanticipated schedule delays and cost overruns in fast-tracking construction. For these reasons, to effectively handle fasttracking change iterations involved in fasttracking need to be identified, and the dynamic behavior of construction resulting from those change iterations must be dealt with in a systematic manner.

\section{CONSTRUCTION CHANGES}

Non-value adding iterations in construction are mainly associated with construction changes. Accordingly, reducing wasteful construction iterations requires effective change management, which should start with the understanding of different characteristics and behavior types of construction changes.

\subsection{Types of Changes}

Normally, construction changes refer to work state, processes, or methods that deviate from the original construction plan or specification. They usually result from work quality, work conditions or scope changes. Meanwhile, changes that have been already made (denoted as Changes as Result in Figure 1) can be the source of subsequent changes in other tasks (denoted as Changes as Source in Figure 1). For example, changes in the design work that have been made by mistake can cause subsequent changes in construction. In this case, the design changes are a result to the designer, while they can be a need for changes to the construction crew. In addition, change can be also seen as an action of making a change (denoted as Change as Behavior in Figure 1), which is further categorized into unintended change and managerial change. Unintended changes occur without the intervention of managerial actions. The arrows labeled $E, F$, and $G$ in Figure 1 illustrate the unintended change process. Meanwhile, managerial changes are made by managerial decisions during quality management or project monitoring and control. As illustrated in Figure 1, once changes occur during construction ( $A$ and $B$ ), changes result in either subsequent changes $(C)$ or rework $(D)$, depending on managerial decisions.

\subsection{Differentiating from Rework}

Both change and rework are done in the form of either 'adding', 'deleting' or 'replacement (deleting and adding)'. However, given the same problem, they have different behavior patterns, since change and rework have different characteristics, as summarized in Table 1. For example, in Case I on Figure 2, given the problem (a hump on the concrete surface), rework would be done by deleting the problem, while change would be done by adding some more concrete. In addition, in Case IV where floor tiling has been finished with less than the required height, although both change and rework have the same behavior pattern (replacement) in solving the problem, the object would be the problem area in rework, while the previous work would be the object in change.

\subsection{Tradeoffs}

In construction, the change option is more general. Since construction has a physical manifestation, construction rework is usually accompanied with the demolition of what have been already built, which normally has a bigger direct impact on the construction performance than the change option. By adopting the change option, it is possible to avoid rework on problematic tasks that may require more resources. However, as previously discussed, changed tasks can also become a change source that can cause other subsequent changes, which might have more impact on the construction performance than the rework option in certain conditions. For example, the increased concrete height in Case I and Case III on Figure 2 may trigger subsequent changes in succeeding tasks, i.e., reducing the size of ventilation ducts. In addition, in Case V on Figure 2 where some of piles have not been correctly positioned, it may be possible to proceed with the superstructure without correcting the position of the piles by changing the position of columns. However, this change option may necessitate unplanned cantilever construction in order to keep the original floor layout, which needs to be evaluated as compared to re-driving the piles. Consequently, a decision on the change option needs to be carefully made based on a good understanding of how changes evolve to nonvalue adding iterations, which can create 
unanticipated and indirect side effects of the decision.

\section{DYNAMIC PROJECT MODEL}

The dynamic project model to be presented has been developed taking into consideration effective change management and operation level construction policy making. To develop the model feedback processes involved in fasttracking construction were identified focusing on how they can trigger non-value adding iterations in the form of construction changes. Having identified feedback processes, the generic construction process, which constitutes the skeleton of the project model, was modeled.

\subsection{Feedback Processes in Construction}

Normally, construction involves feedback processes represented in the causal loop diagram on Figure 3-a, 3-b, 3-c, and 3-d. When tasks and resources are available, first, the upstream work, based on which the available tasks will be carried out, is reviewed before commissioning resources for the tasks. During the review process, problems made in the upstream work can be discovered. Once they are found, depending on managerial decisions, workers may request the upstream worker to correct the problematic work. More upstream hidden changes can cause more requests for the upstream work reprocess, which results in more pending tasks $(A)$ and schedule delays $(B)$ in the downstream work. Otherwise, workers construct tasks not having problems in the associated upstream tasks, with given resources. Once tasks are completed, the construction performance on the tasks is periodically monitored or inspected to see whether or not the target quality is met and the intended functions are achieved. Through this quality management process, a decision on whether releasing the completed tasks or not can be made.

Unintended changes resulting from low work quality, bad work conditions or frequent scope changes can cause managerial changes $(C)$, rework $(D)$, or hidden changes $(E)$, depending on managers' willingness to adopt the change option and quality management thoroughness. The more construction is delayed the more often the change option tends to be adopted $(F)$, in order to avoid rework, which is normally perceived to have a bigger impact on the schedule performance. However, such managerial efforts can create unplanned and/or indirect side effects. As a result of feedbacks involved in the processes $(F, G, H, I, J)$, managerial changes can trigger further delays as well as rework. As diagramed in Figure 3-a, managerial changes trigger reprocess iterations of tasks that have been already released (refer to the definition of managerial changes in Table 1), while rework delays the construction progress by creating reprocess iterations of tasks that have not been released.

In addition, delays also may make quality management efforts less thorough $(K)$, which results in more hidden changes $(L)$. During the downstream review process, hidden changes released from the upstream work can be discovered. Once they are found, depending on managerial decisions, downstream workers request the upstream worker to correct the hidden changes. As a result, more hidden changes can cause more correction requests from the downstream $(M)$, which also can delay the construction progress as a result of subsequent feedback processes $(N, I, J)$ diagramed in Figure 3-b.

Furthermore, increased willingness to adopt managerial changes also can increase subsequent changes in the downstream work $(O)$, which delays the downstream work process. Consequently, reprocess requests from the downstream work are also delayed $(R)$, which again impacts the schedule performance of the activity that has originated changes $(N, I, J)$. Meanwhile, lowered quality management thoroughness creates more hidden changes $(L)$. Increased hidden changes can deteriorate the work quality of the downstream work, which creates more reprocess iterations of the downstream tasks. This also impacts the upstream schedule performance through $(R, N, I, J)$. All of these feedback processes can impact the construction performance, combined with resource availability, construction policies, and people' reactions to work conditions and policies.

\subsection{Model Description}

Based on feedback processes and relationships among construction variables in the causal loop diagrams on Figure 3, the quantitative 
representation of the generic construction process has been modeled using system dynamics modeling techniques. In addition, other supporting model structures for resources, scopes, and quality have been also developed. Detailed model descriptions are found in Park (2001).

\section{CASE STUDIES}

The developed dynamic project model is being applied to the construction of 27 bridges in order to help effectively manage changes and prepare a robust construction plan. The construction is a part of a $\$ 400$ million Design/Build/Operate/Transfer project for roadway improvements along State Route 3 from its intersection with State Route 128 in Burlington, MA north to its terminus at the New Hampshire border. The development process is expected to span 42 months with the project completion achieved in February, 2004. The project scope includes widening the 21mile of the state roadway and the existing 15 underpass bridges, and renovating 12 overpass bridges. This paper presents a case study of the Treble Cove Road Bridge Construction, one of bridge renovation projects, demonstrating how the case project has suffered from changes and providing construction policies to minimize change impact on the project performance including labor policies and schedule buffering.

\subsection{Simulating the Actual Performance}

The simulated actual duration is 559 working days. This is 168 days longer than the CPMbased duration of the base case, which is 391 working days. The difference in the completion time is mainly caused by a lot of non-value adding iterations among design and construction activities. Actually, the construction team is working to address such issues that the design development of the Treble Cove Road Bridge project was already shown significant delay and construction has not been yet started. Some of these issues are due to the fact that this project was awarded to the contractor before the detailed scope of the project has been established. As a result, changes on the design work were frequently requested from the owner side during sketch plan, final plan, and shop drawing submittal, which resulted in a lot of design iterations. In addition, this case project was the first design/build contract for the members of development team in the owner side, expected level of coordination among the owner, designer and constructor has not been met to date and design iterations encountered were difficult to handle. Based on interviews with the design and construction team, these challenges in the design development were represented as 'Highly Unreliable' in the project model and the simulated actual durations for those activities show how much non-value adding iterations caused by changes can affect the project progress in a quantitative manner.

\subsection{Policy Implications}

In order to examine the effectiveness of different construction policies, simulations were done adapting the actual case with different scenarios for managerial decisions on change or rework, labor control, buffering, and some important time variables. As a result of the simulations, the following policy implications were obtained (refer to Figure 4 to see the model simulation).

First, a higher managerial change ratio tended to reduce costs but lengthen the project duration. However, it is hard to generalize this result, since the tradeoff of change and rework is highly dependent on construction system conditions at the time when a decision is made. This implies that effective change management requires an operational level approach rather than a long term policy, and it should be accompanied with well preparation of relatively long-term policies such as labor control policies, schedule buffering and delivery methods.

In connection with labor policies, flexible labor control was found to be effective for the case project in terms of schedule and cost reduction. In contrast, overtime contributed to facilitating the project schedule to some extent but its effectiveness is questioned, once increased project costs are considered. Overtime applied for the case project lowered productivity and increased change rate, as workers' fatigue was accumulated. In fact, the effectiveness of labor control policies can vary depending on the nature of a project. However, 
many success stories of concurrent construction projects like our case project confirm the above policy implications, demonstrating that having flexibility in labor control contributes to reducing the project duration and costs by assigning workforce in a timely manner.

In addition, the case project has been simulated with various buffering scenarios; not having buffer, having uniform buffer, and having buffer based on activities' characteristics. The simulation results showed that applied buffers contributes to reducing the upstream change impact and non-value adding iterations. As a result, the resource idle time and waste were reduced, which made it possible to more effectively utilize given workforce. In particular, buffering based on activities' characteristics turned out to have most effectively enhanced the schedule and cost performance.

Lastly, the simulations done with different time variable scenarios demonstrate that shortening a required time for labor hiring and RFI reply contributes to enhancing the project schedule and cost performance. In particular, RFI reply time greatly affected the project performance. Shortening RFI reply time by half could facilitate the project progress by $12 \%$ and reduce the project costs by $10 \%$. In contrast, when RFI reply time was doubled, duration and costs were increased by $29 \%$ and $24 \%$ respectively. These simulation results imply that for this case project, coordination among the project functions is crucial to the success of the project. Consequently, the decision-making process in design and construction should be shortened and information flow among project functions should be streamlined to assist in reducing the decision-making time.

In conclusion, although the obtained simulation results can vary depending on project settings, they well demonstrate how the dynamic project model can contribute to enhancing the project performance in a real world setting by providing effective change management plans and policy guidelines. Additionally, the simulation results also imply that model-based construction policies can be more effective, when combined with other managerial efforts such as reducing a process time and increasing the level of coordination among project functions.

\section{CONCLUSIONS}

Construction involves a lot of non valueadding change iterations due to its structural problems, in particular when construction is performed concurrently. This has necessitated the development of a tool that can effectively manage construction changes. This paper addressed the challenging issue by introducing the concept of dynamic change management to construction planning and management. Although the research results discussed thus far need to be further refined and developed, they demonstrated that the dynamic change management approach and the developed project model would help prepare a more robust construction plan against uncertainties and provide policy guidelines, by taking into consideration the context in which a construction project is being developed.

\section{REFERENCES}

Fazio, P., Moselhi, O., Theberge, P. and Revay, S. (1988), Design Impact of Construction Fast-Track, Construction Management and Economics, Vol. 6, No. 2, pp 195-208

Ford, D and Sterman, J. (1997), Dynamic Modeling of Product Development Processes, Sloan School of Management, Working Paper 3943-97, MIT, Cambridge, MA

Huovila, P., Koskela, L., and Lautanala, M. (1994), Fast or Concurrent: The Art of Getting Construction Improved, Proceedings, pp 143-158, The second workshop on lean construction, Santiago

Kwak, S. (1995), "Policy Analysis of Hanford Tank Farm Operations with System Dynamics Approach", Doctoral Thesis, Dept. of Nuclear Engineering, MIT, Cambridge, MA

Lyneis, J. (1999), "Dynamics of Project Performance", Course Material, Dept. of Civil and Envr. Eng. at MIT 
Park, M. (2001), "Dynamic Planning and Control Methodology for Large-Scale Concurrent Construction Projects", Doctoral Thesis, Dept. of Civil Engineering, MIT, Cambridge, MA

Pena-Mora, F and Park, M. (2001), "Robust Control of Cost Impact on Fasttracking Building Construction Projects', Journal of Construction Engineering and Management, ASCE
Tighe, J (1991), Benefits of Fast Tracking are a Myth, International Journal of Project Management, Vol. 9, No. 1, pp 49-51

Williams, G.V. (1995), Fast-Track Pros and Cons: Considerations for Industrial Projects, Journal of Management in Engineering, Vol. 11 No 5, pp 24-32, Sep/Oct. 1995

External Scope Changes

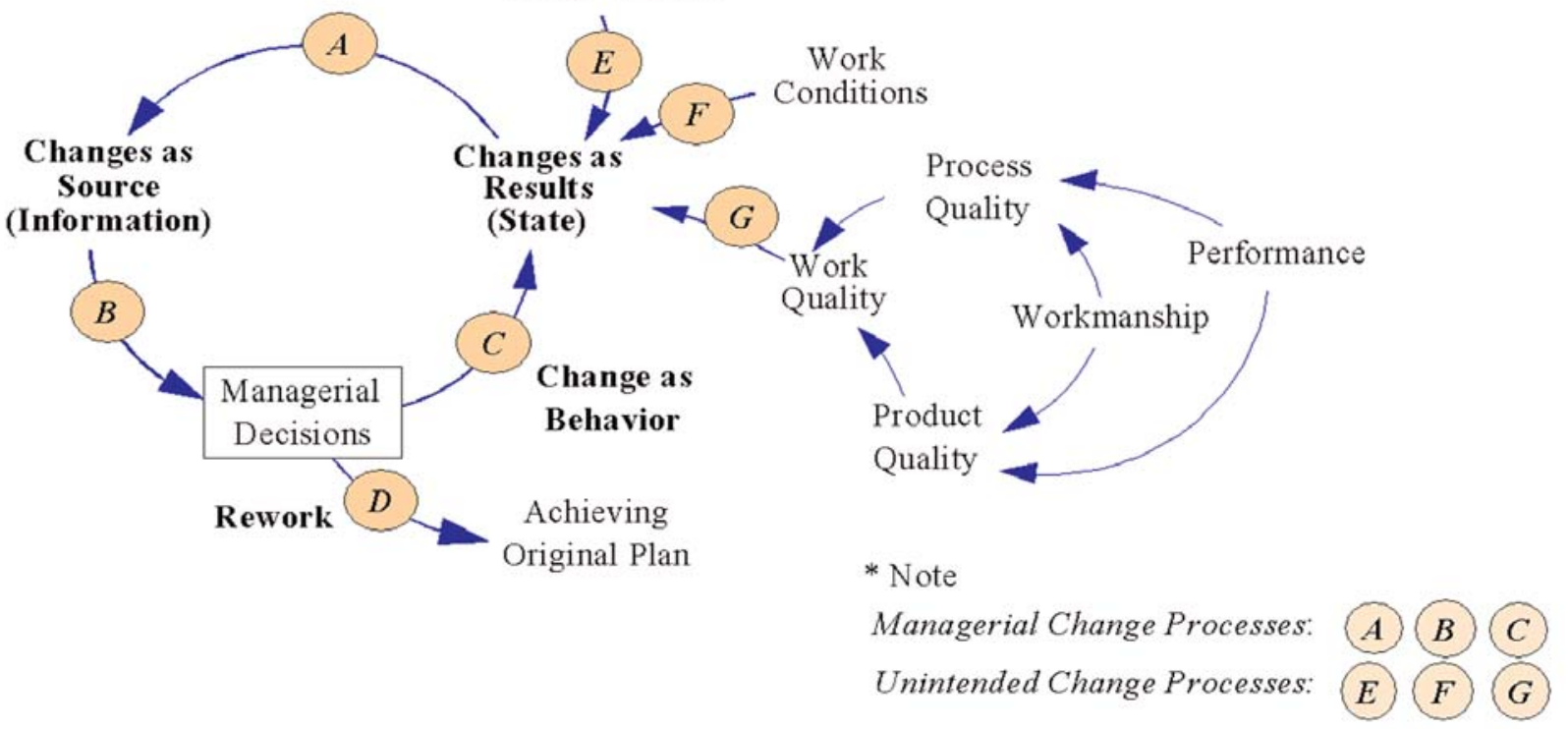

Table 1: Characteristics of Change and Rework

\begin{tabular}{|l|l|l|l|l|}
\hline Des. & Purposes & Object & $\begin{array}{l}\text { Scope of } \\
\text { Work }\end{array}$ & $\begin{array}{l}\text { Triggering } \\
\text { Another } \\
\text { Changes }\end{array}$ \\
\hline $\begin{array}{l}\text { Managerial } \\
\text { Changes }\end{array}$ & $\begin{array}{l}\text { Minimizing the impact of } \\
\text { changes that have already } \\
\text { occurred by adopting a } \\
\text { different method or process } \\
\text { than in the original plan and } \\
\text { specification. }\end{array}$ & $\begin{array}{l}\text { Preceding or } \\
\text { succeeding } \\
\text { tasks }\end{array}$ & $\begin{array}{l}\text { Vary, } \\
\text { depending on } \\
\text { sensitivity }\end{array}$ & May trigger \\
\hline Rework & $\begin{array}{l}\text { Achieving what are } \\
\text { originally intended in the } \\
\text { plan and specification. }\end{array}$ & $\begin{array}{l}\text { The } \\
\text { problematic } \\
\text { tasks }\end{array}$ & $\begin{array}{l}\text { Same as the } \\
\text { scope of } \\
\text { problematic } \\
\text { tasks }\end{array}$ & None \\
\hline
\end{tabular}






Figure 2: Behaviors of Change and Rework

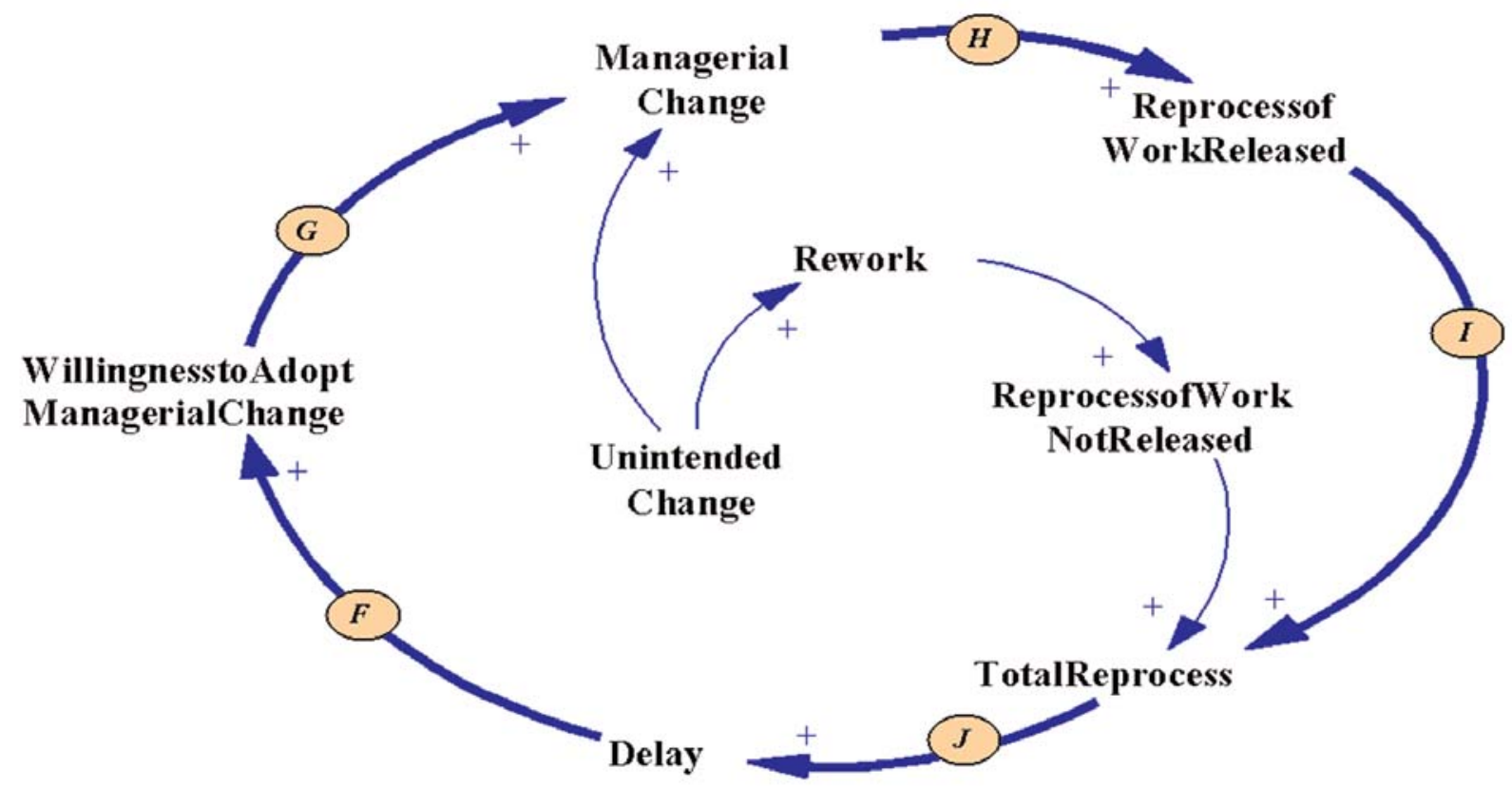

Figure 3a: Change Option Loop 
Figure 3b: Quality Management Thoroughness Loop

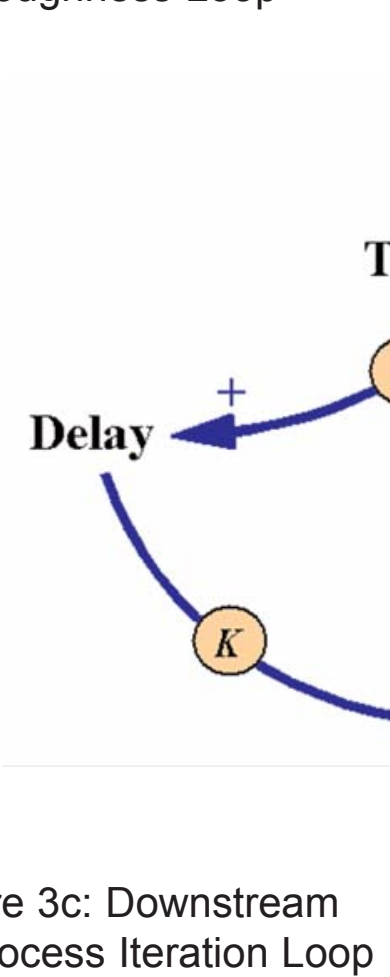

Reprocess Iteration Loop

WillingnesstoAdopt ManagerialChange

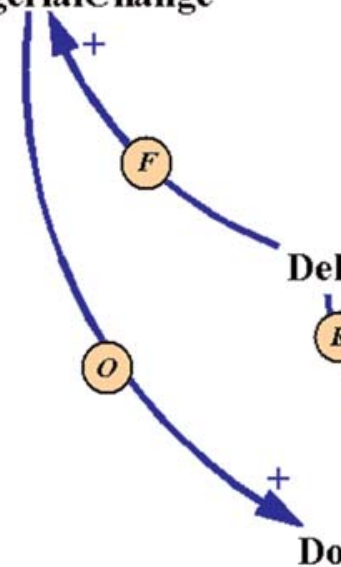

Reprocessof

WorkReleased

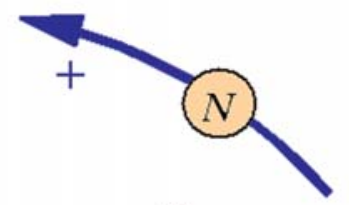

ReprocessRequest

FromDownstream

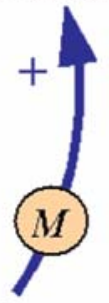

HiddenChanges

QualityManagement

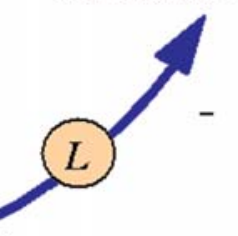

_ Thoroughness 


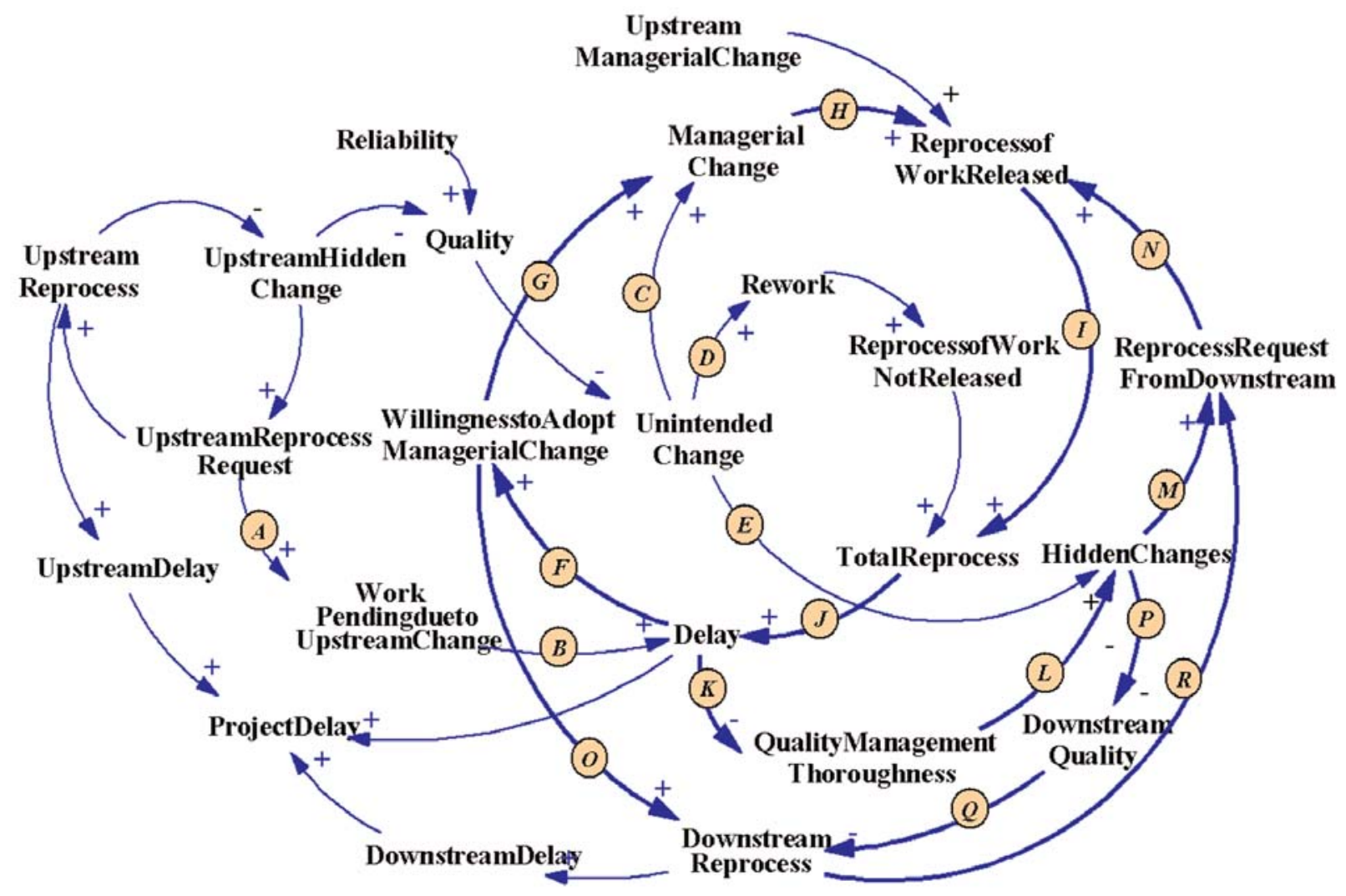

Figure 3d: Feedback Processes in Construction Activities

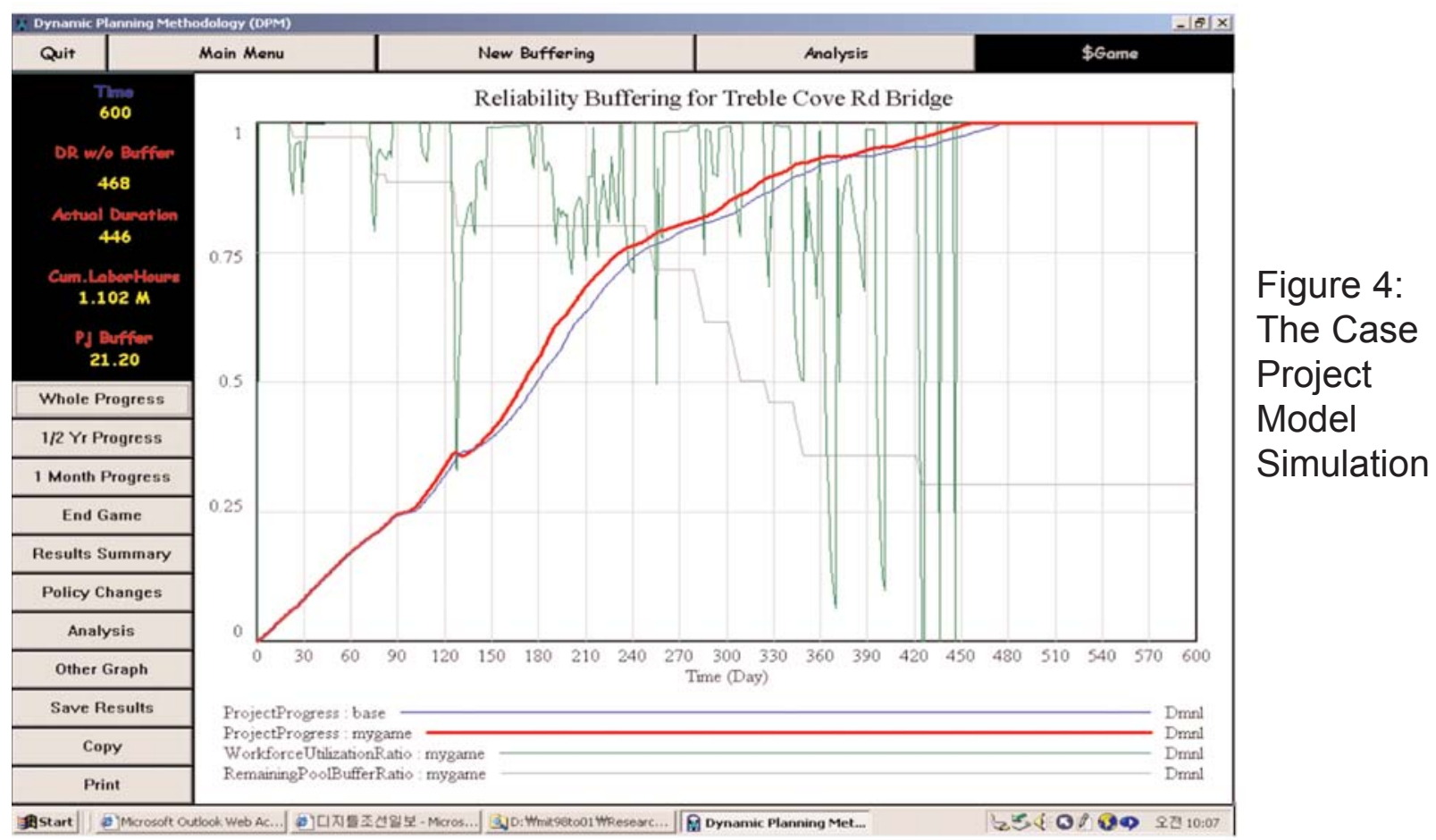

